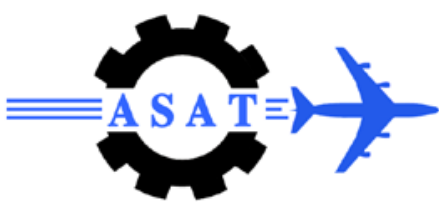

\title{
Preliminary Design of the Tail Unit of a Newly Designed Agricultural Aircraft
}

\author{
A. M. Gubaratalla Ali ${ }^{*}$, M. Elhadi A. E. ${ }^{\dagger}$
}

\begin{abstract}
This project work undertakes the task of analyzing stresses and preliminary designing of the tail structure members of a newly designed light agricultural aircraft.

Schrenk's method has been used for estimating the span-wise lift distribution, while the tail weight was assumed to be uniformly distribution along the span. Hence, the shear force and bending moment diagrams have been obtained. Accordingly, the working shear and bending stresses within the flight envelope have been calculated.

The design has been based on the limit load while the maximum bending and shear values are encountered at the tail root, with the gust load being neglected. The bending and shear margins are found to be positive along the semi-span/height, which shows good enough strength.
\end{abstract}

Keywords: Agricultural aircraft, Preliminary design, tail unit, Schrenk’s method.

\section{Nomenclature:}

A Stringer area, in ${ }^{2}$

$\mathrm{Al}$ Aluminum,

F Force, lbf

I Second moment of area, in ${ }^{4}$

M Bending moment, lbf.ft

V Velocity, fps

M.S Margin of Safety,

n Load factor,

q Shear flow, lbf/in

S Shear force, lbf

S.F Safety Factor,

$\mathrm{t}$ Thickness, in

$\mathrm{x}, \mathrm{y}$ \&z Coordinates, in

$\sigma \quad$ Normal stress, psi

$\tau \quad$ Shear stress, psi

* B.Sc. Graduate, Sudan University of Science and Technology, Khartoum, Sudan, jubara@w.cn

† Assistant Professor, Karary University, Khartoum, Sudan, mohadi20@hotmail.com 


\section{Introduction:}

Tail Unit is an aviation term used to describe the rear section of an aircraft. The tail is also known as empennage or tail assembly; all three terms may be used interchangeably [1].

The tail gives stability to the aircraft and controls the flight dynamics of pitch and yaw. Structurally, the empennage consists of the entire tail assembly, including the fin, the tailplane and the part of the fuselage "cone" to which these are attached. On an airliner this would be all the flying and control surfaces behind the rear pressure bulkhead.

The tailplane comprises the tail-mounted fixed horizontal stabilizer and movable elevator. Besides its plan-form, it is characterized by:

1. No. of tailplanes: from 0 (Tailless or canard) to 3 (Roe triplane)

2. Location of tailplane: mounted high, mid or low on the fuselage, fin or tail booms.

3. Fixed stabilizer and movable elevator surfaces, or a single combined stabilizer or flying tail.

The fin comprises the fixed vertical stabilizer and rudder. Besides its profile, it is characterized by:

1. No. of fins: from 0 (McDonnell Douglas X-36) to 3 (Lockheed Constellation).

2. Location of fins on the fuselage: over or under tailplane, tail booms or wings.

Agricultural aviation is a term used to refer to: agricultural, forestry, fishing and public health; where such use is a tool and not just a mean of transport. Agricultural aviation is in fact aerial application; i.e. the distribution of chemical and seeds from the air on the surface of the land, water or on vegetation growing there.

\section{Objective}

This research work undertakes the tasks of conducting size of typical tail structural components and analysis the structure in order to determine the margin of safety in different flight conditions.

\section{Case Study}

SEAD-8 is a local agricultural aircraft designed in Sudan University of Science and Technology to minimize the operating cost of such types and to accompany the present aviation development in SUDAN.

This A/C met FAR 23-Requirement for following performance characteristics: Stall speed, landing distance, take-off distance, climb rate and Cruise speed. Table (1) displays SEAD-8 specifications, while Table (2) shows those for the tail unit.

Table (1): SEAD-8 specifications

\begin{tabular}{l|c}
\hline \hline Payload, [lbf] & 2,204 \\
\hline Range, [ft.] & 73,440 \\
\hline Endurance, [min] & 60 \\
\hline Initial rate of climb, [fps] & 1.17 \\
\hline Service ceiling, [ft.] & 10,000 \\
\hline Absolute ceiling, [ft.] & 25,000 \\
\hline Engine Type & PT6A-11AG \\
\hline Field length, [ft.] & $3280-3940$ \\
\hline Field width, [ft.] & $33-50$ \\
\hline \hline
\end{tabular}


Table (2): Tail unit specifications

\begin{tabular}{l|c|c}
\hline \multicolumn{1}{c|}{ Parameter } & Tailplane & Fin \\
\hline \hline Area, [ft. ${ }^{2}$ ] & 67.2 & 24.8 \\
\hline Span / height, [ft.] & 14.2 & 5.6 \\
\hline Root chord, [ft.] & 4.7 & 5 \\
\hline Flap chord, [ft.] & 1.15 & 1.33 \\
\hline Aspect ratio & 3.021 & 1.279 \\
\hline Taper ratio & 1 & 0.74 \\
\hline Airfoil type & NACA 0009 & NACA 0012 \\
\hline Weight, [lbf] & 83.79 & 35.79 \\
\hline \hline
\end{tabular}

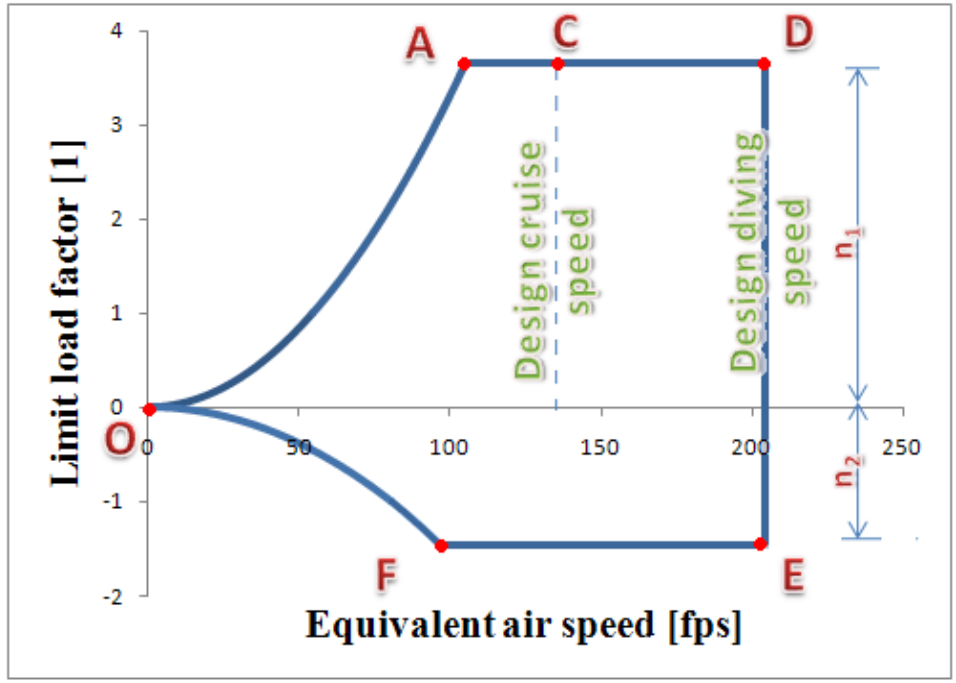

Fig. 1 Sead-8 V-n diagram

\section{Procedure}

The main stages are:

1. Loads estimation and stress analysis.

2. Members sizing.

3. Structure analysis.

\section{Loads Estimation and Stresses Analysis}

The semi-span is divided into 20 equal elements. All loads are based on point (D) in the "V-n diagram" as shown in Fig. 1, where the speed (V) and load factor (n) are maximum and at sea level altitude where the density is maximum.

Initially the aerodynamic loads need to be determined, so it has been decided to use the Schrenk's method to calculate the lift distribution [2].

The values of limit shear forces and limit bending moment are calculated for each section $(\mathrm{z})$ and then multiplied by a safety factor of (1.5). 


\section{Members Sizing}

The type of this structure is a semi-monocoque statically determinate structure that consists of several stringers, ribs and skin.

The size process based on fail-safe principle "Accepts that there is a chance that a part of the structure fails, however, there should be no chance of the whole structure failing” [3].

For both the tailplane and the fin, the stringers positions are chosen to be as shown in Table (3) and also demonstrated in Fig. 2.

Table (3): Stringers position

\begin{tabular}{l|c|c|c|c|c|c|c|c}
\hline \hline Stringer No. & 1 & 2 & 3 & 4 & 5 & 6 & 7 & 8 \\
\hline Position (x/C) & 0.1 & 0.3 & 0.5 & 0.7 & 0.7 & 0.5 & 0.3 & 0.1 \\
\hline \hline
\end{tabular}

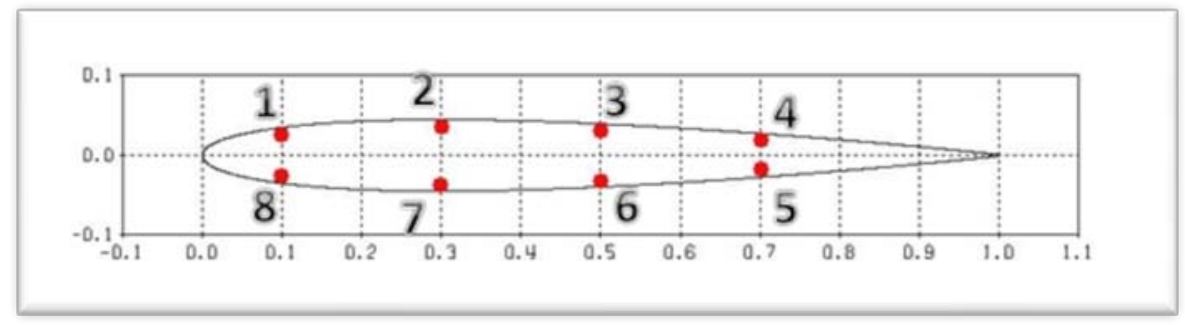

Fig. 2 Stringers and booms positions and numbers

The sizing process is based on a group of several Al 2024 alloys as shown in Table (4).

Table (4): Al 2024 alloys properties

\begin{tabular}{c|l|c|c|c}
\hline \hline No. & Alloy Name & Yield Stress [psi] & Ultimate Stress [psi] & Shear Strength [psi] \\
\hline \hline 1 & $2024-0$ & 27,000 & 11,000 & 18,000 \\
\hline 2 & $2024-\mathrm{T} 3$ & 70,000 & 50,000 & 41,000 \\
\hline 3 & $2024-\mathrm{T} 361$ & 72,000 & 57,000 & 42,000 \\
\hline 4 & $2024-\mathrm{T} 4$ & 68,000 & 47,000 & 41,000 \\
\hline 5 & $2024-\mathrm{T} 6$ & 61,900 & 50,000 & 41,000 \\
\hline 6 & $2024-\mathrm{T} 81$ & 70,300 & 65,300 & 42,800 \\
\hline 7 & $2024-\mathrm{T} 851$ & 66,000 & 58,000 & 42,900 \\
\hline 8 & $2024-\mathrm{T} 86$ & 74,700 & 63,800 & 45,000 \\
\hline \hline
\end{tabular}

\section{Structure Analysis}

Complex structural sections may be idealized into simpler 'mechanical model' forms [4]. The stringers have a small cross sectional dimensions compared with the complete a/f section. Thus, the variation in stress over the cross-section of a stringer due to, say, bending would be small. Furthermore, the difference between the distances of the stringer centroids and the adjacent skin from the section axis is small.

It would be reasonable to assume therefore that the direct stress is constant over the stringer cross-sections. Thus the stringers could be replaced by concentrations of area, known as booms, over which the direct stress is constant and which are located along the mid-line of the skin.

Then the margin of safety had been calculated. 


\section{Equations}

$S_{x}=\int_{\text {root }}^{\text {tip }} F_{x} \cdot d z$

$S_{y}=\int_{\text {root }}^{\text {tip }} F_{y} \cdot d z$

$M_{x}=\int_{\text {root }}^{\text {tip }} S_{y} \cdot d z$

$M_{y}=\int_{\text {root }}^{\text {tip }} S_{x} \cdot d z$

The governing equation for the boom to restrict the bending stress is:

$\sigma_{z}=\frac{M_{x}}{I_{x x}} y \pm \frac{M_{y}}{I_{y y}} x$

The governing equation for the skin to restrict the shear stress is:

$\tau=\frac{q_{s}}{t}$

$q_{s}=-\frac{S_{x}}{I_{y y}} \sum A x-\frac{S_{y}}{I_{x x}} \sum A y$

M.S $=\frac{\text { al lowable stress }}{\text { actual stress }}-1$

\section{Results \& Discussions}

\section{Tailplane}

The typical Tailplane structure for the a/c is sized with positive limit load factor is equal to 3.8 and span equal to $14.2 \mathrm{ft}$. as shown in Fig. 2.

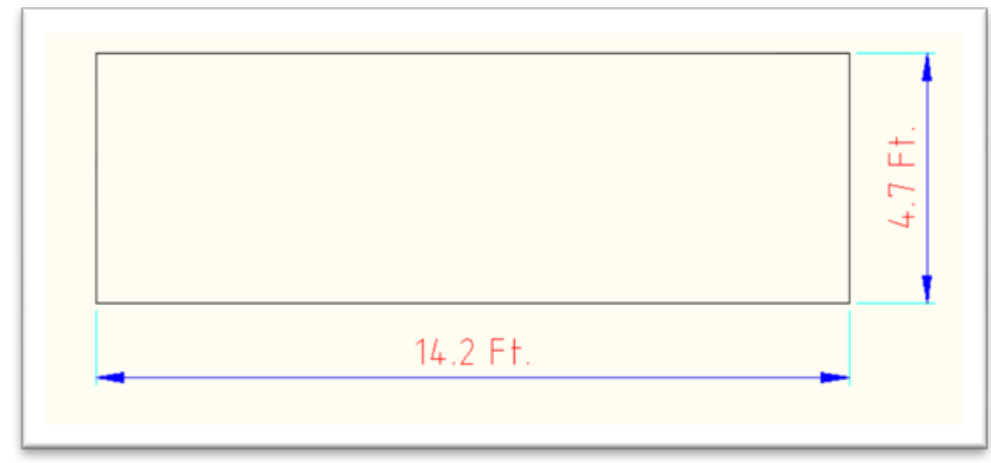

Fig. 3 Tailplane plan form

The shear forces are shown in Fig. 4. They varied smoothly and linearly along the semi-span with a maximum values being at root and then become (zero) at the tip. 


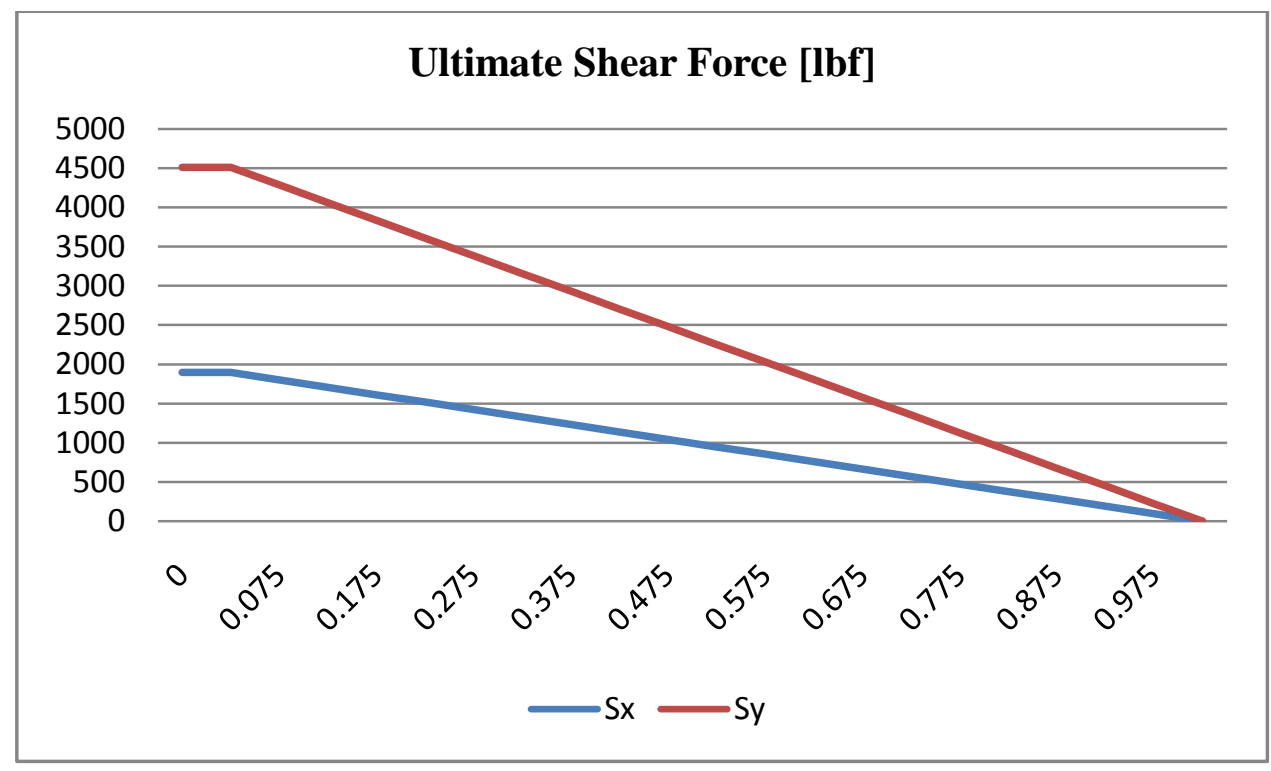

Fig (4): The ultimate shear forces along the semi-span

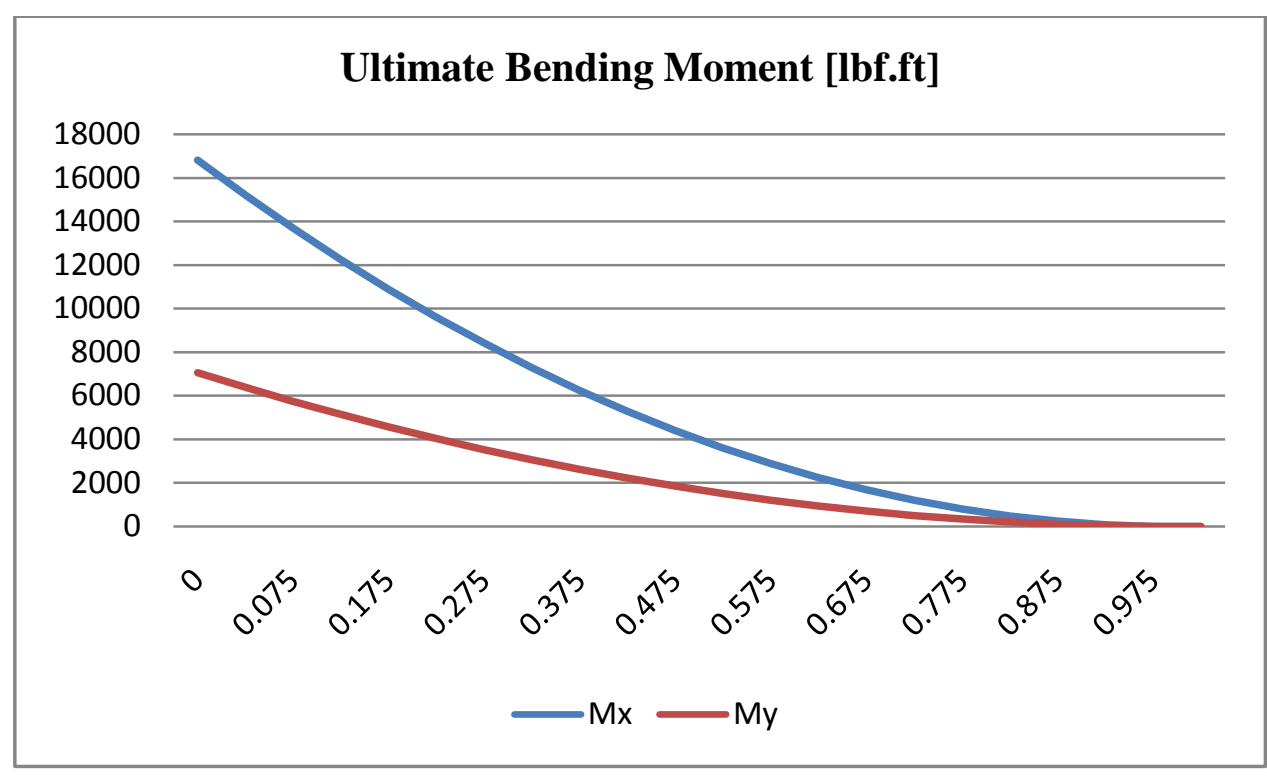

Fig. 5 The ultimate bending moments along the semi-span

The bending moments are shown in Fig. 5 . They varied curvedly along the semi-span with a maximum values being at the root and then become (zero) at the tip.

The maximum values of bending Moments, used to calculate the bending stress where the maximum values were found in booms \#2, \#3, \#6 and \#7 "as shown in Fig. 2. Then the required area (stringer) and the required thickness (skin) are calculated at all stress ratios for all selected materials.

The maximum values of ultimate shear forces are used to calculate the shear flow, then the minimum required thickness (skin) are calculated at all stress ratios for all selected materials. The structure weight is calculated for all materials and all stress ratios and plotted in Fig. 6 as shown below: 


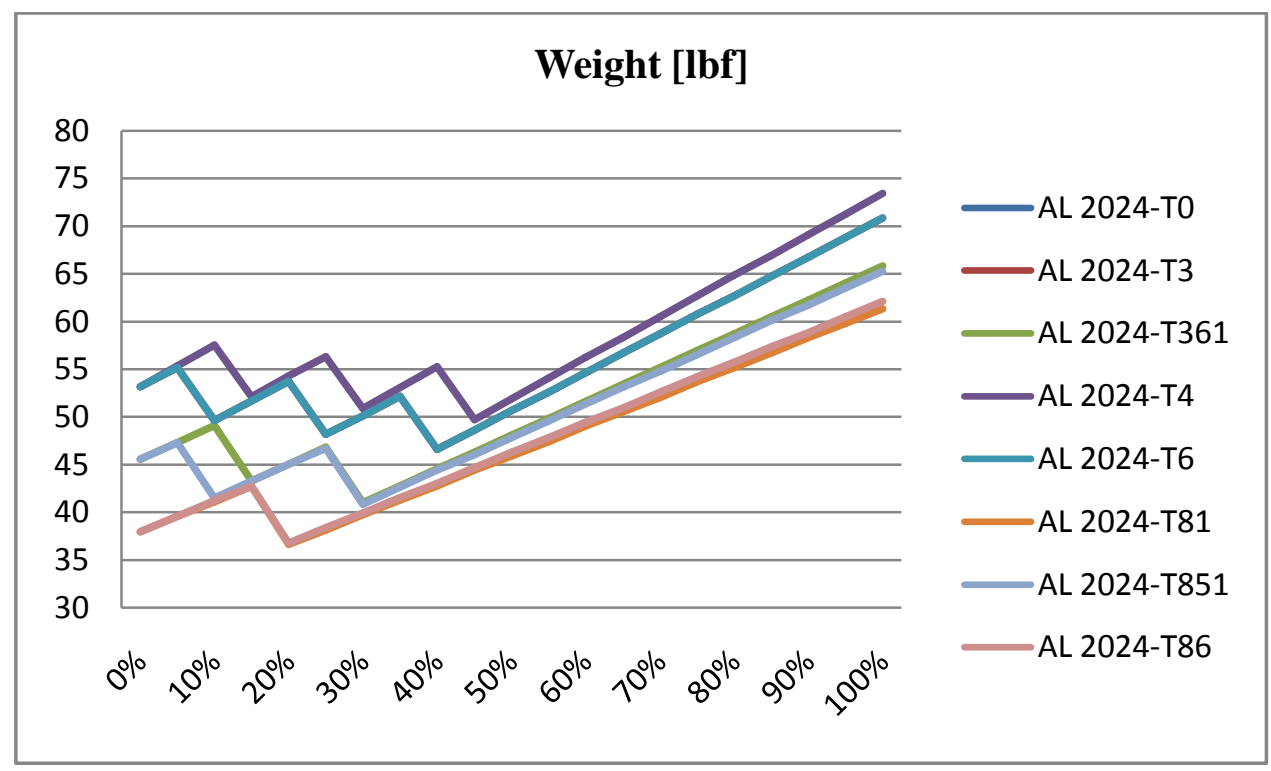

Fig. 6 Structure weight vs. stringer stress ratio

From Fig. 6, the minimum structure weight was found when using the alloy Al 2024-T81 and when the stringers carry 20\% of the bending stress as shown if Fig. 7 and Fig. 8.

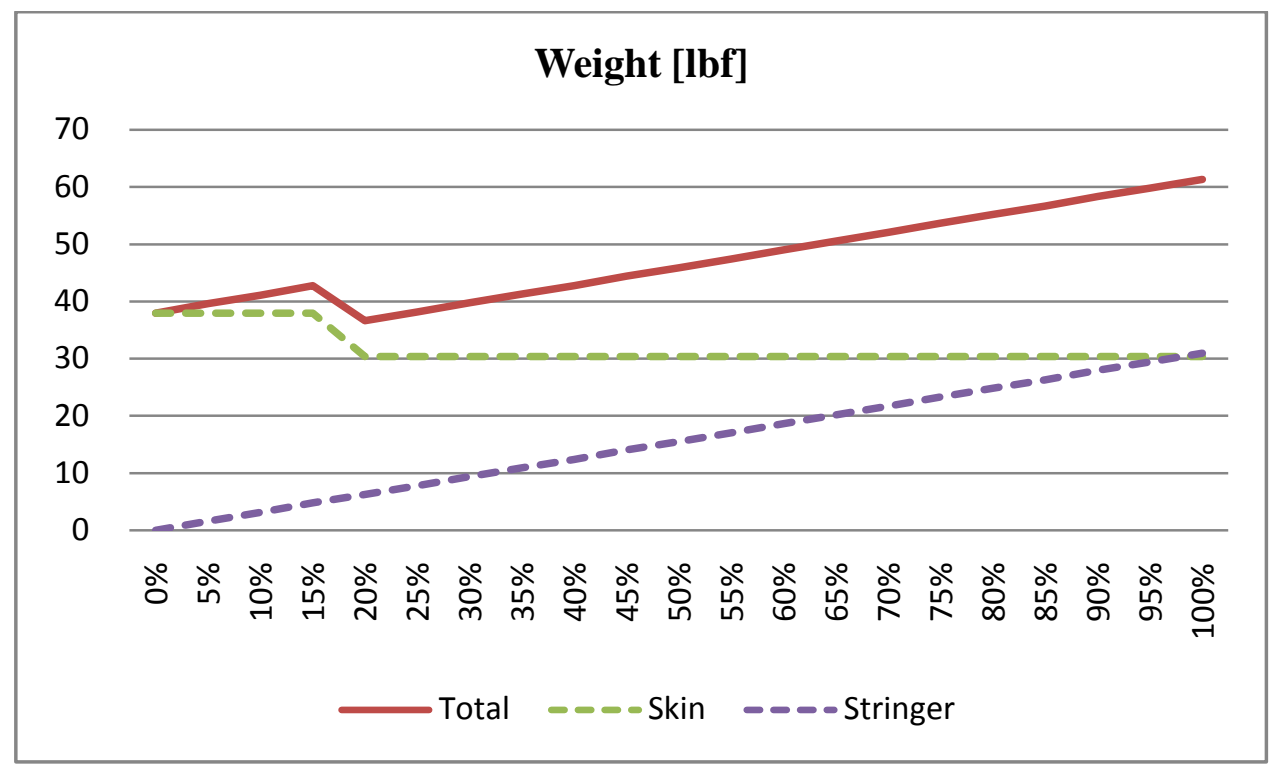

Fig. 7 Weight vs. stringer stress ratio 


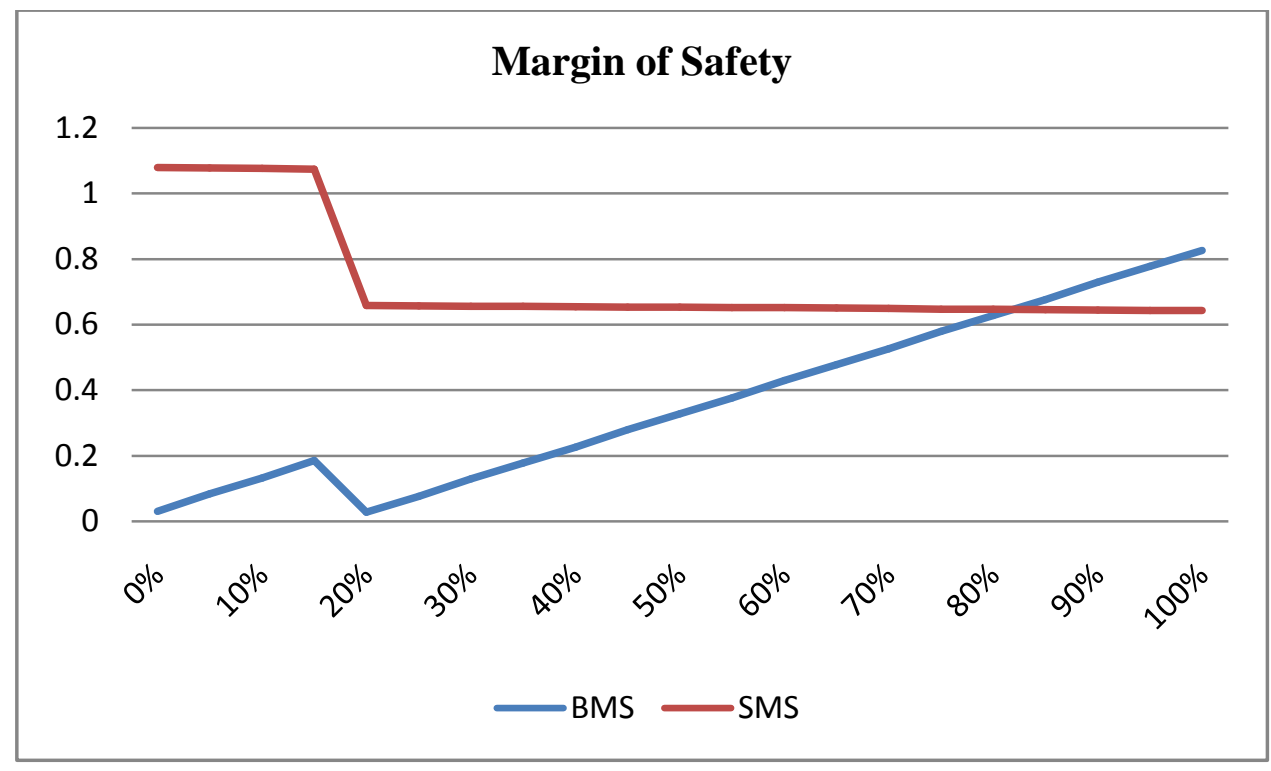

Fig. 8 Margin of safety vs. stringer stress ratio

From Fig. 7 and Fig. 8, the optimum design will be: stringer area of $0.046 \mathrm{in}^{2}$ and skin thickness of 0.020 in.

Then the shear margin of safety and bending margin of safety are shown in Fig. 9 and Fig. 10 respectively. They varied curvedly along the semi-span with a minimum values being at the root and then goes to infinity at the tip.

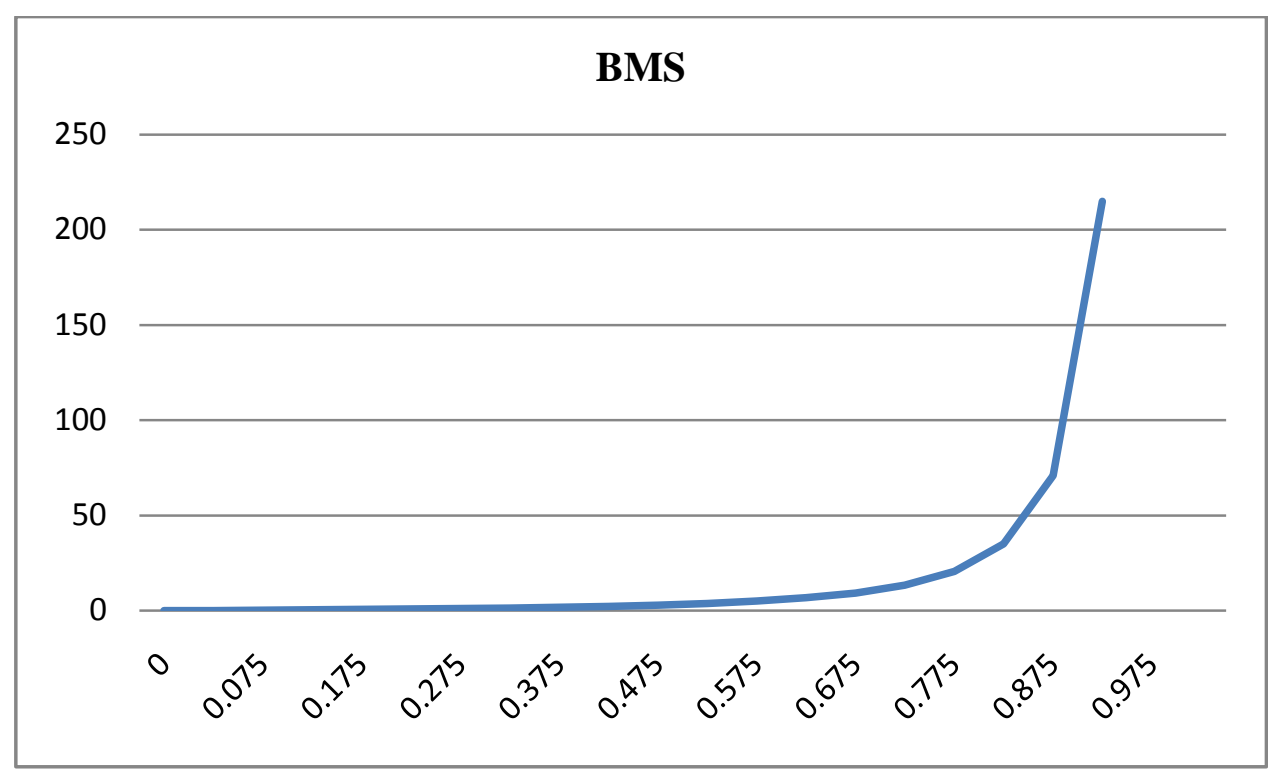

Fig. 9 Bending margin of safety along the semi-span 


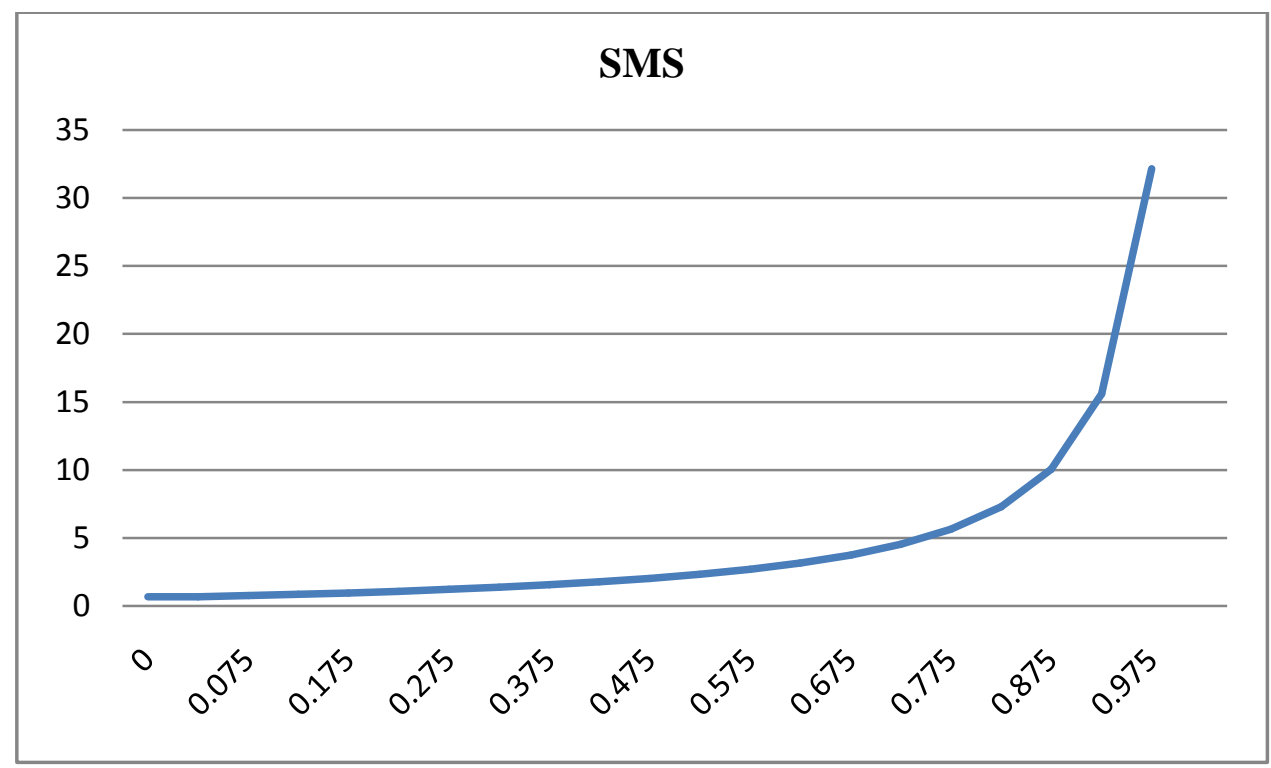

Fig. 10 Shear margin of safety along the semi-span

Fin

The typical fin structure for the A/C is sized with positive limit load factor is equal to 3.8 and height equal to $5.6 \mathrm{ft}$. as shown in Fig. 11.

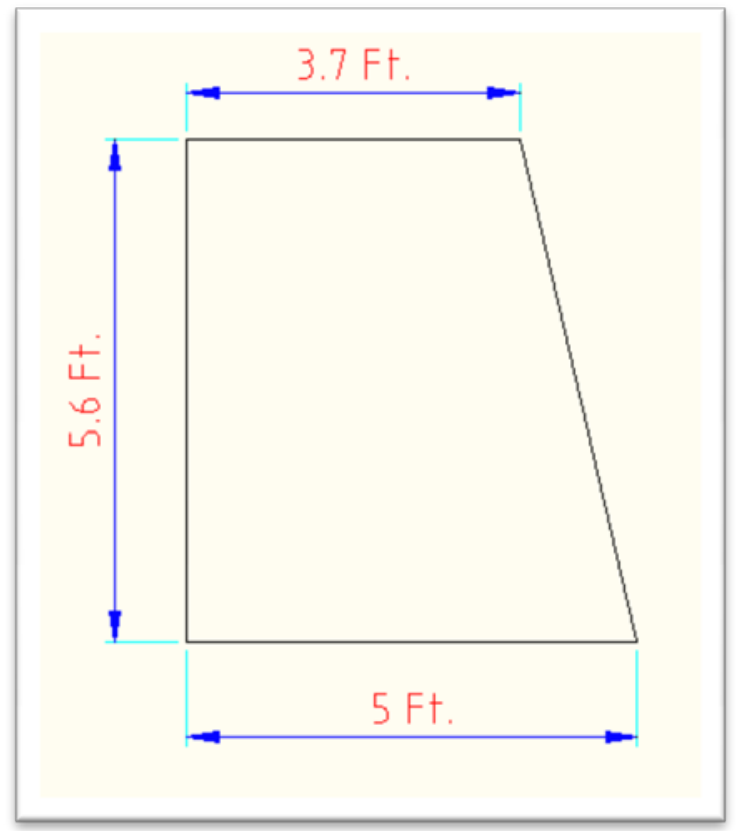

Fig. 11 Fin side view

The shear forces are shown in Fig. 12. They varied smoothly and linearly along the height with a maximum values being at root and then become (zero) at the tip. 


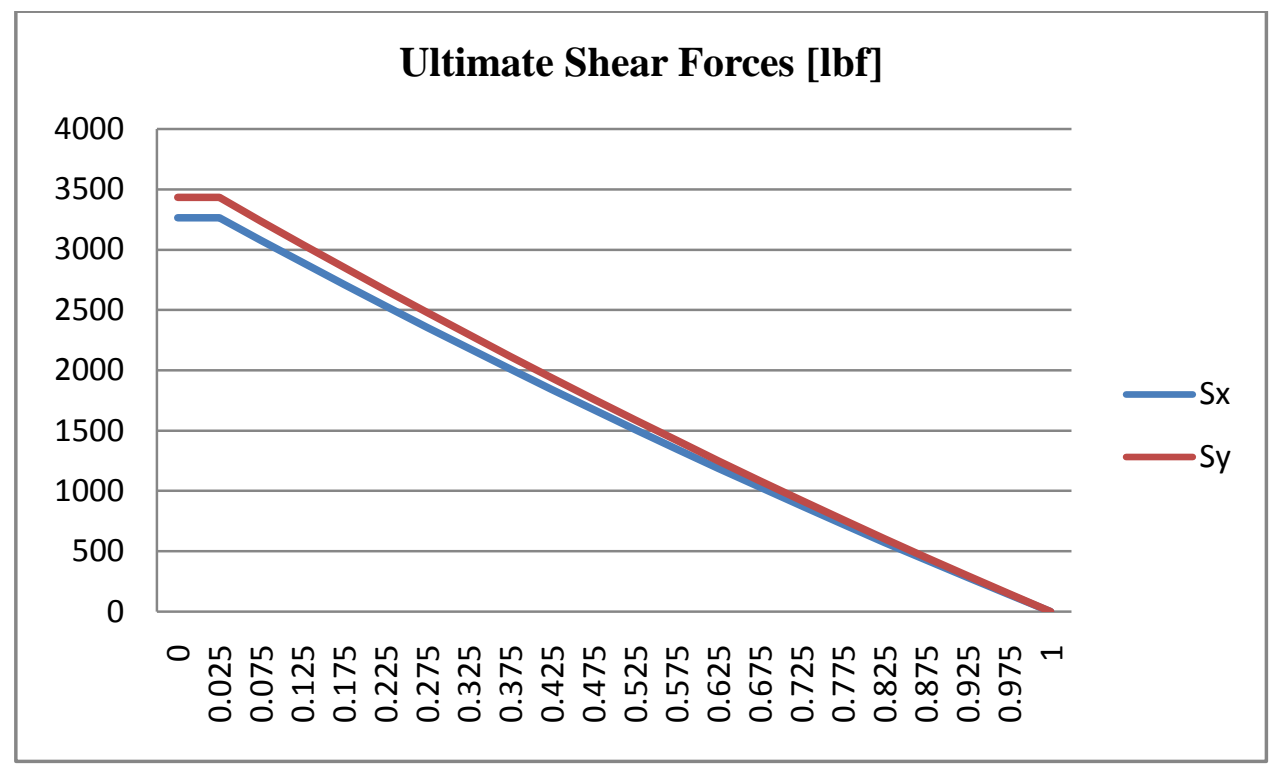

Fig. 12 The ultimate shear forces along the height

The bending moments are shown if Fig. 13. They varied curvedly along the height with a maximum values being at the root and then become (zero) at the tip.

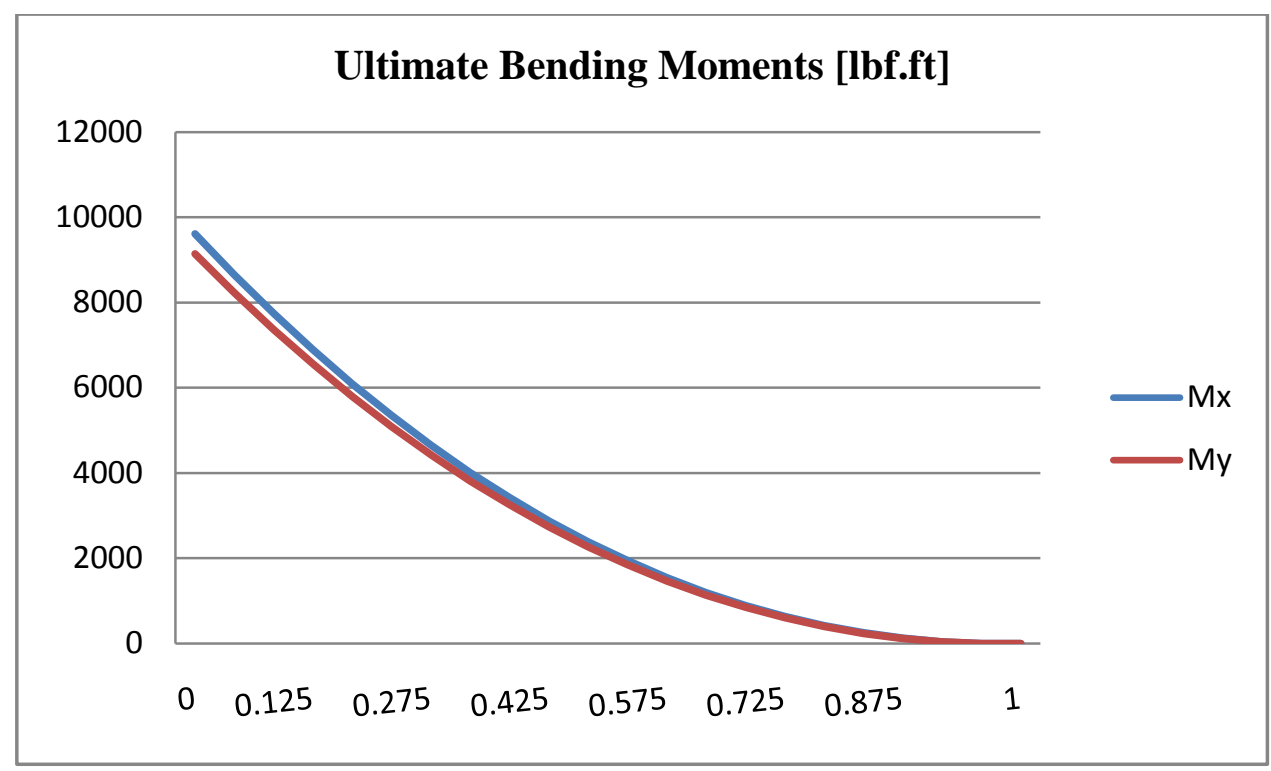

Fig. 13 The ultimate bending moments along the height

The maximum values of ultimate bending moments are used to calculate the bending stress where the maximum values are found in booms \#2, \#3, \#6 and \#7 "as shown if Fig. 2". Then the required area (stringer) and the required thickness (skin) are calculated at all stress ratios for all selected materials.

The maximum values of ultimate shear forces are used to calculate the shear flow, then the minimum required thickness (skin) are calculated at all stress ratios for all selected materials. The structure weight is calculated for all materials and all stress ratios and plotted in Fig. 14 as shown below. 


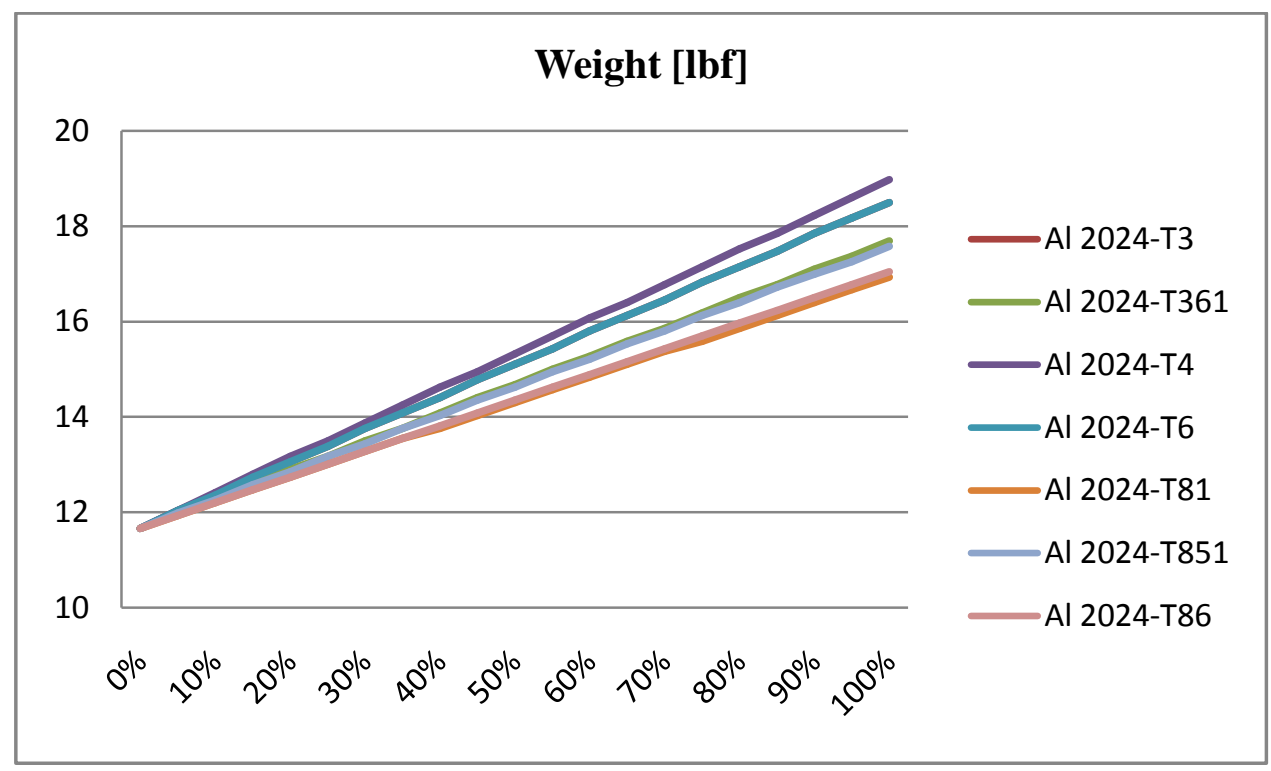

Fig. 14 Structure weight vs. stringer stress ratio

From Fig. 14, the minimum structure weight was found when using the alloy Al 2024-T3 when the stringers carry 0\% of the bending stress "full stressed skin' as shown in Fig. 15 and Fig. 16.

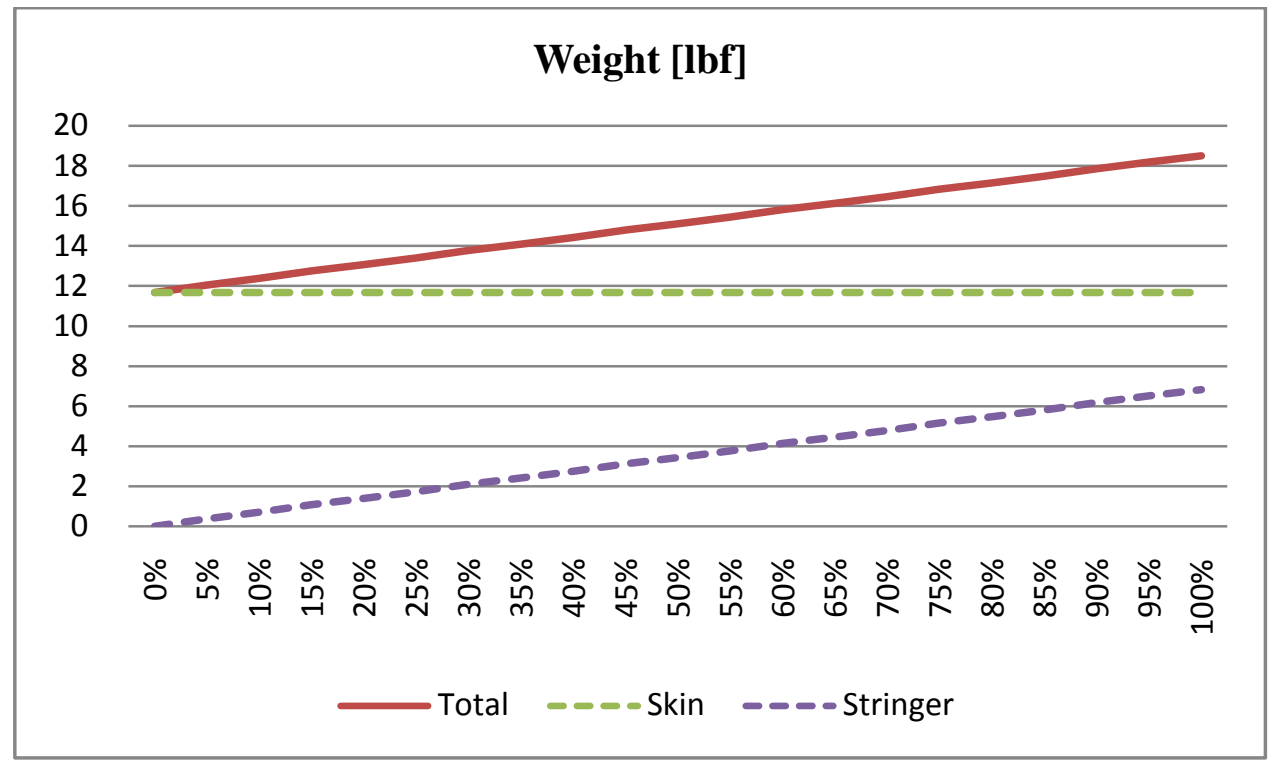

Fig. 15 Structure weight vs. stringer stress ratio. 


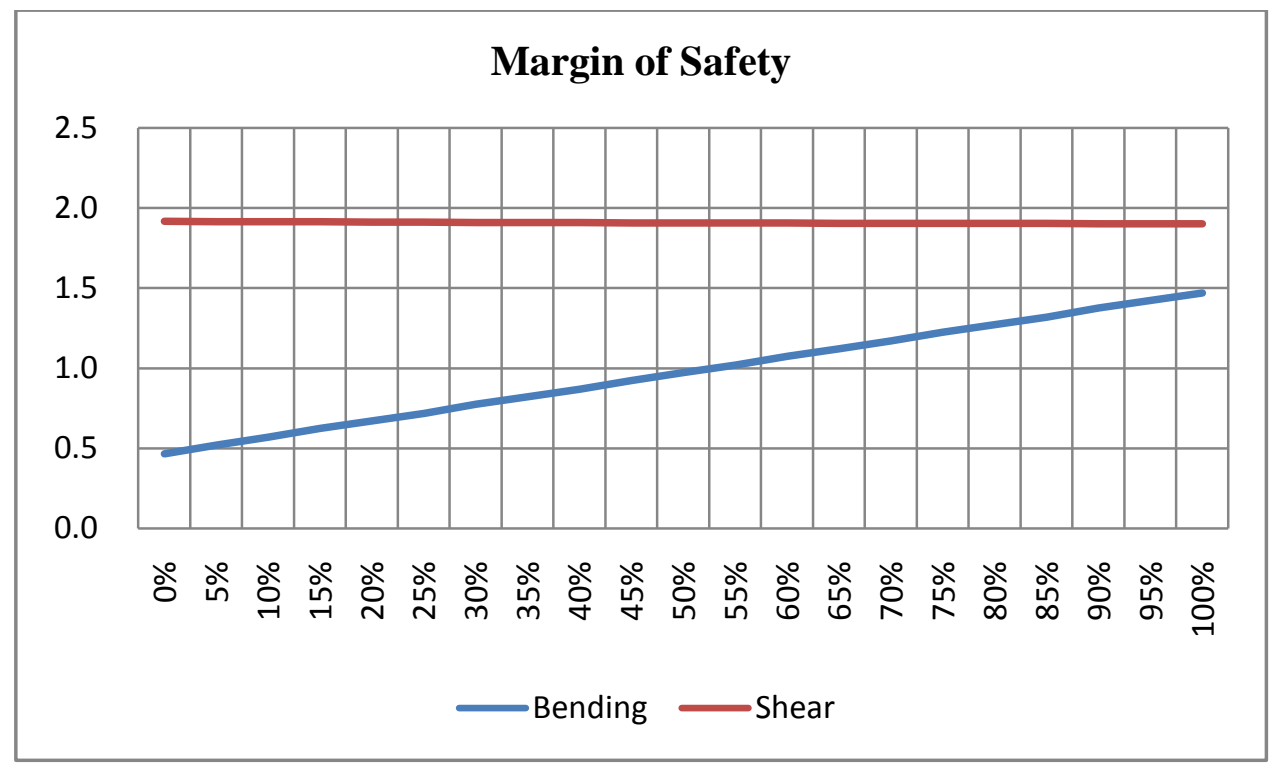

Fig (16): Margin of Safety vs. Stringer Stress Ratio.

From Figs. 15 and 16, the optimum design will be: No. stringer and skin thickness of 0.020 in.

Then the shear margin of safety and bending margin of safety are shown in Fig. 17 and Fig. 18 respectively. They varied curvedly along the semi-span with a minimum values being at the root and then goes to infinity at the tip.

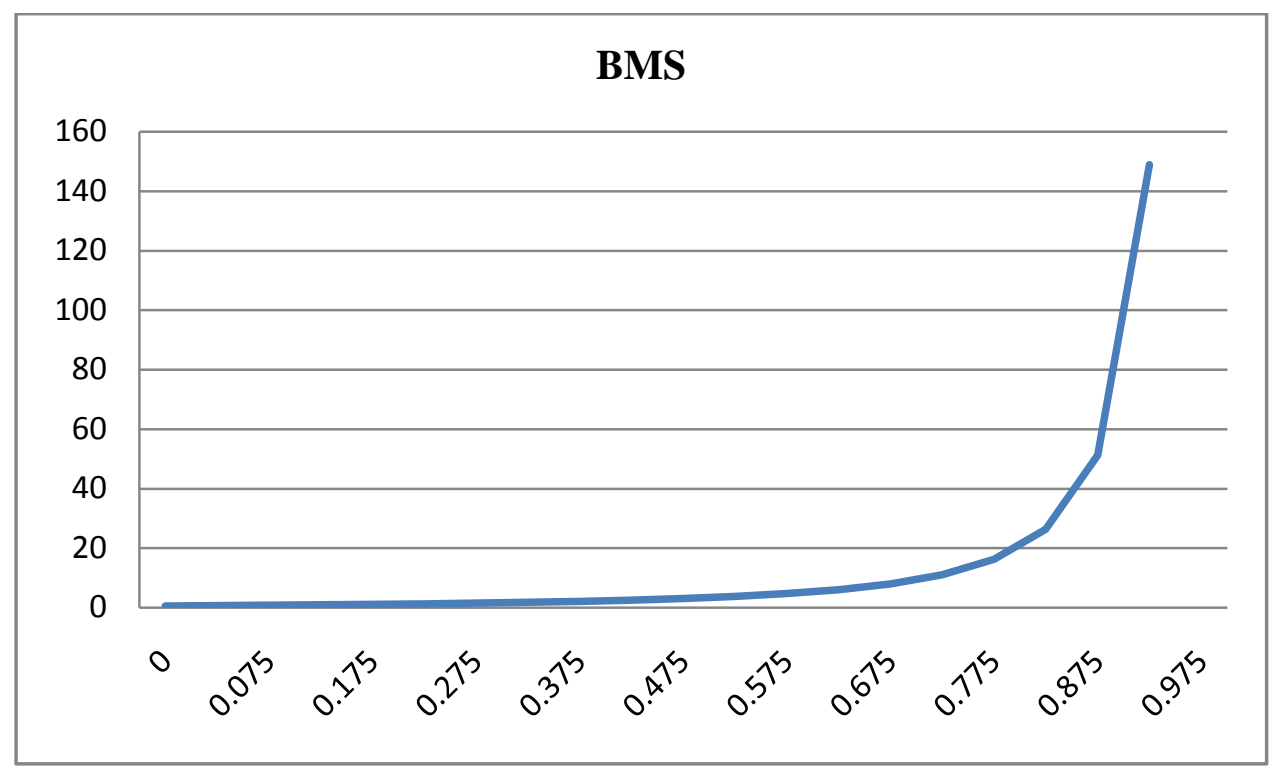

Fig. 17 Bending margin of safety along the height. 


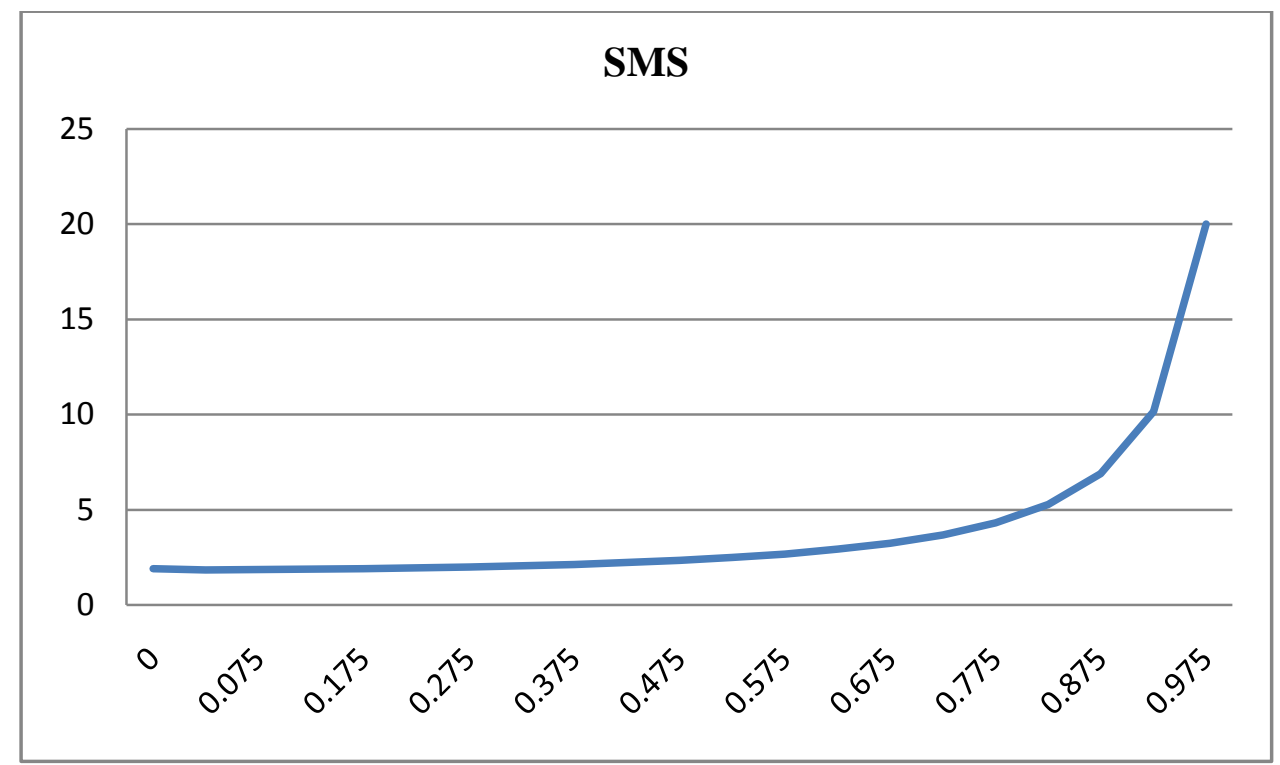

Fig. 18 shear margin of safety along the heigh.

Table (5): Margin of safety in different flight conditions

\begin{tabular}{l|c|c|c|c}
\hline \hline & \multicolumn{2}{|c|}{ BMS } & \multicolumn{2}{c}{ SMS } \\
\cline { 2 - 5 } & Cruise & Design & Cruise & Design \\
\hline \hline Tailplane & 0.735 & 0.030 & 2.510 & 1.079 \\
\hline Fin & 2.562 & 0.701 & 5.393 & 2.053 \\
\hline \hline
\end{tabular}

\section{Conclusion}

The main objective of this project was to conduct the size of the main structural component of the tail unit of a typical agricultural aircraft.

The Tailplane constructed of: eight stiffeners "stringers" with cross section area of (0.046) inch $^{2}$ and skin with a thickness of (0.02) inch.

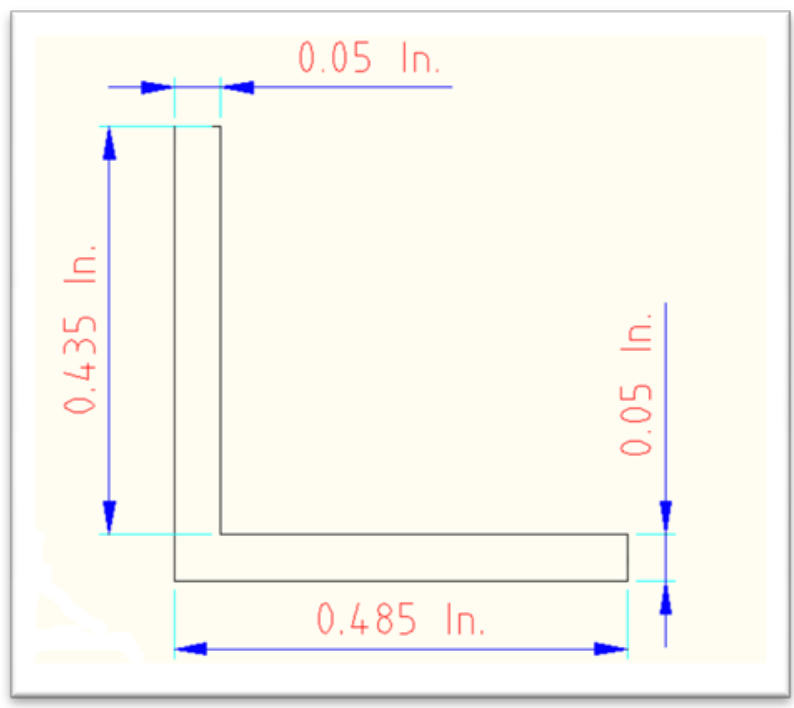

Fig. 19 Tailplane stringer cross-section. 
Where the fin is constructed from: zero stiffeners and full stressed skin with a thickness of (0.02) inch.

The major concluded points that could be drawn are summarized below:

o For the current design, the bending and shear margins of safety are positive from root up to tip in both the tailplane and the fin.

o For the bending and shear margins of safety on point (D) in the "V-n Diagram", the obtained values are good enough which shows ample strength for the structure.

o The structure is safe within the design speed that the bending and shear margins of safety are both positive.

More analysis is required to verify the above conclusions for the various flight conditions, namely by adding the loads which have been neglected in present work. Also - as this work is a preliminary design only - additional work is required to investigate for vibration, buckling and aeroelastic characteristics.

\section{References}

[1] Wikipedia, “Empennage”, 18 December 2004, Adrienne Alix, France, 8 June 2010, http://en.wikipedia.org/wiki/Empennage

[2] David J Peery, “Aircraft Structure”, $1^{\text {st }}$ edition, McGraw Hill, New York, 1976.

[3] Bruhn E. F., "Analysis and Design of Flight Vehicle Structures”, Jacobs Pub; Revised Edition (June 1973), ISBN: 0961523409.

[4] T. H. G. Megson, “Aircraft Structures for engineering students”, $3^{\text {rd }}$ Edition, Butterworth, Heinemann, 2001. 